\title{
Systematic review of miscellaneous agents for the management of oral mucositis in cancer patients
}

\author{
Siri Beier Jensen • Virginia Jarvis • Yehuda Zadik • Andrei Barasch • \\ Anura Ariyawardana • Allan Hovan • Noam Yarom • Rajesh V. Lalla • \\ Joanne Bowen - Sharon Elad • For the Mucositis Study Group of the Multinational \\ Association of Supportive Care in Cancer/International \\ Society of Oral Oncology (MASCC/ISOO)
}

Received: 3 May 2013 / Accepted: 19 June 2013 / Published online: 31 July 2013

(C) Springer-Verlag Berlin Heidelberg 2013

\begin{abstract}
Purpose The aim of this systematic review was to analyze the available literature and define clinical practice guidelines for the use of the following agents for the prevention and treatment of oral mucositis $(\mathrm{OM})$ : allopurinol, midline mucosa-sparing radiation blocks, payayor, pentoxifylline, timing of radiation therapy (RT) (morning versus late
\end{abstract}

\section{S. B. Jensen $(\bowtie)$}

Section of Oral Medicine, Clinical Oral Physiology, Oral Pathology and Anatomy, Department of Odontology, Faculty of Health and Medical Sciences, University of Copenhagen, Nørre Allé 20,

2200 N Copenhagen, Denmark

e-mail: sirib@sund.ku.dk

\section{Jarvis}

Department of Nursing, The Ottawa Hospital Cancer Centre,

Ottawa, Canada

e-mail: gjarvis@ottawahospital.on.ca

\section{Y. Zadik}

Israeli Air Force Surgeon General Headquarters, and Department of Oral Medicine, Israel Defense Forces Medical Corps,

Tel Hashomer, Israel

e-mail: yzadik@gmail.com

\section{Y. Zadik}

Department of Oral Medicine, Hebrew University-Hadassah School of Dental Medicine, Jerusalem, Israel

\section{A. Barasch}

Department of Dental Medicine, Winthrop University Hospital, Mineola, NY, USA

e-mail: ABarasch@Winthrop.org

\section{A. Ariyawardana}

School of Medicine and Dentistry, James Cook University,

Cairns, Australia

e-mail: anura.ariyawardana@jcu.edu.au afternoon), pilocarpine, bethanechol, chewing gum, propantheline, and tetrachlorodecaoxide.

Methods A systematic review was conducted by the Mucositis Study Group of the Multinational Association of Supportive Care in Cancer/International Society for Oral Oncology (MASCC/ISOO). The body of evidence for each intervention, in each cancer treatment setting, was assigned an evidence

A. Ariyawardana

Griffith Health Institute, Griffith University, Gold Coast, Australia

A. Hovan

Department of Dentistry, BC Cancer Agency,

Vancouver, BC, Canada

e-mail: ahovan@bccancer.bc.ca

N. Yarom

Department of Oral and Maxillofacial Surgery, Sheba Medical

Center, Tel-Hashomer, Israel

e-mail: noamyar@post.tau.ac.il

N. Yarom

Department of Oral Pathology and Oral Medicine, School of Dental Medicine, Tel-Aviv University, Tel-Aviv, Israel

R. V. Lalla

Section of Oral Medicine and Neag Comprehensive Cancer Center,

University of Connecticut Health Center, Farmington, CT, USA

e-mail: Lalla@uchc.edu

J. Bowen

School of Medical Sciences, The University of Adelaide,

Adelaide, Australia

e-mail: joanne.bowen@adelaide.edu.au

S. Elad

Division of Oral Medicine, Eastman Institute for Oral Medicine,

University of Rochester Medical Center, Rochester, NY, USA

e-mail: SElad@URMC.Rochester.edu 
level. Based on the evidence level, one of the following three guideline determinations was possible: recommendation, suggestion, no guideline possible.

Results A total of 32 papers across 10 interventions were examined. New suggestions were developed against the use of systemic pilocarpine administered orally for prevention of OM during RT in head and neck cancer patients and in patients receiving high-dose chemotherapy, with or without total body irradiation, prior to hematopoietic stem cell transplantation. A suggestion was also made against the use of systemic pentoxifylline administered orally for the prevention of $\mathrm{OM}$ in patients undergoing bone marrow transplantation. No guideline was possible for any other agent reviewed due to inadequate and/or conflicting evidence.

Conclusions None of the agents reviewed was determined to be effective for the prevention or treatment of OM. Two agents, pilocarpine and pentoxifylline, were determined to be ineffective, in the populations listed above. Additional well-designed research is needed on other interventions.

Keywords Oral mucositis · Cancer therapy · Supportive · Palliative $\cdot$ Prevention $\cdot$ Treatment $\cdot$ Saliva

\section{Introduction}

Oral mucositis $(\mathrm{OM})$ is a significant toxicity of chemotherapy (CT) and/or head and neck radiation in cancer patients. Ulcerative $\mathrm{OM}$ is very painful and often requires systemic narcotics for pain relief. It also negatively affects diet, nutrition, oral hygiene and quality of life. In immunosuppressed patients, secondary infection of OM lesions can lead to sepsis. Due to the significant morbidity associated with OM, it sometimes necessitates unwanted dose reductions or treatment interruptions in cancer therapy, which can impact on the cancer prognosis. The management of OM in most patients is palliative and centered on relief of symptoms. A large number of agents have been tested for OM, with generally inconsistent results.

The Mucositis Study Group of the Multinational Association of Supportive Care in Cancer/International Society of Oral Oncology (MASCC/ISOO) has published clinical practice guidelines for mucositis, in order to facilitate evidence-based care and improve outcomes. The last update of these guidelines was published in 2007 [1]. Due to the significant increase in the clinical OM literature, an effort to update these guidelines was recently undertaken. As part of this update, agents reviewed were classified into different groups based on their predominant mechanism of action (such as cytokines and growth factors, cryotherapy, laser therapy, etc.). The results relating to some of these groups have been published [2-9, 12]. However, a number of agents did not fit into these categories due to a different proposed mechanism of action for mucositis. These agents were classified as "miscellaneous agents" and included the following: allopurinol, midline mucosa-sparing radiation blocks, payayor, pentoxifylline, radiation therapy (RT) in the morning versus late afternoon, stimulation/inhibition of salivary secretion (pilocarpine, bethanechol, chewing gum, propantheline), and tetrachlorodecaoxide. The aim of this project was to systematically review the available literature and define evidence-based clinical practice guidelines for the use of these miscellaneous agents for the prevention and treatment of OM. The agents included here covered a wide range of rationales and potential mechanisms for interference in the pathogenesis of $\mathrm{OM}$ and thus will be addressed alphabetically and in clusters by mechanism.

\section{Methods}

The methods are described in detail in Bowen et al. [3] and Elad et al. [4]. Briefly, a literature search for relevant papers indexed in MEDLINE until 31 December 2010 was conducted using OVID/MEDLINE, with papers selected for review based on defined inclusion and exclusion criteria. The list of intervention keywords used for the literature search of this section included: allopurinol, bethanechol, chewing gum, pentoxifylline, pilocarpine, propantheline, anticholinergic, radiation: morning versus evening, midline mucosa-sparing blocks, natural, alternative, complementary, gum, xanthan. Papers were reviewed by two independent calibrated reviewers and data was extracted using a standard electronic form. Studies were evaluated based on the list of major and minor flaws published by Hadorn [10]. A level of evidence was assigned for each intervention based on the Somerfield criteria [11]. A well-designed study was defined as a study with no major flaws per the Hadorn criteria.

Findings from the reviewed studies were integrated into guidelines based on the overall level of evidence for each intervention. Guidelines were classified into three types: recommendation, suggestion, and no guideline possible.

Guidelines were separated based on (1) the aim of the intervention (prevention or treatment of mucositis); (2) the treatment modality [RT, CT, chemoradiotherapy, or high-dose conditioning therapy for hematopoietic stem cell transplantation (HSCT)], and (3) the route of administration of the intervention.

\section{Results}

The literature search identified a total of 99 papers that were retrieved for detailed analysis. Of these, 18 papers were excluded based on our inclusion/exclusion criteria (listed in Bowen et al. [3]). Of the remaining 81 papers, 49 papers pertained to agents of natural origin and the results on those agents will be reported separately [12]. This manuscript reports the results of the review of the remaining 32 papers that tested interventions which did not fit in any of the other 
categories and were classified as "miscellaneous agents". The included papers related to allopurinol $(n=12)$, midline mucosa-sparing blocks $(n=1)$, payayor $(n=1)$, pentoxifylline $(n=6)$, RT in the morning versus late afternoon $(n=2)$, pilocarpine $(n=4)$, bethanechol $(n=1)$, chewing gum $(n=1)$, propantheline $(n=3)$, and tetrachlorodecaoxide $(n=1)$.

\section{Allopurinol}

Allopurinol is a xanthine oxidase inhibitor used for the treatment of gout. We identified 12 studies that have addressed the effects on OM of allopurinol administered in the form of mouthwash, ice balls or systemically. Table 1 summarizes the results of the systematic review on the use of allopurinol. The major findings are presented below per the allopurinol route of administration.

Three studies, including an open label non-randomized controlled study and two case-series, evaluated per oral administration of allopurinol for the prevention of $\mathrm{OM}$ in patients receiving 5-fluorouracil (5-FU) based CT. These studies demonstrated a lack of effectiveness for mucositis prevention in both hematological cancer $[13,14]$ and solid cancer [15] patient populations.

No guideline was possible due to the low level of evidence (Level V).

Only one small cohort study with a retrospective control group addressed a special formula of allopurinol mouth ice ball combining the pharmacologic effect and the cryotherapy effect [16]. This formula was tested in advanced colon cancer patients for the prevention of OM and showed effectiveness; however, the study design had significant confounding limitations.

No guideline was possible due to insufficient evidence.

Allopurinol was assessed as a mouthwash for the prevention of OM in seven studies of patients with solid cancers having CT.

Two of these were randomized controlled trials $[17,18]$. One of the studies was a well-designed double-blind, randomized, placebo-controlled, cross-over study [18], while the other had significant limitations in design and implementation [17]. Both studies enrolled patients with various malignant disorders (colorectal, breast, gastric, pancreatic, and esophageal cancers) and found no significant effect of allopurinol rinses on 5-FU-induced mucositis. The remaining five studies of allopurinol administered as a mouthwash were a "before and after study", two case series and two nonrandomized controlled trials. Four of these studies reported a reduction of oral toxicity of 5-FU in solid cancers [19-22] while one reported no benefit [23].

No guideline was possible due to the conflicting evidence.

The only study which tested allopurinol for the treatment of mucositis was a randomized controlled study [24]. In this study, allopurinol was evaluated as a mouthwash for patients with advanced solid cancers during CT. This study found that allopurinol was effective; however, the study design and implementation had significant limitations.

No guideline was possible due to insufficient evidence.

Table 1 Summary of study findings for allopurinol

\begin{tabular}{|c|c|c|c|c|c|c|c|c|c|}
\hline $\begin{array}{l}\text { Name of } \\
\text { agent }\end{array}$ & $\begin{array}{l}\text { Route of } \\
\text { administration }\end{array}$ & Cancer type & $\begin{array}{l}\text { Treatment } \\
\text { modality }\end{array}$ & Indication & Author, year & Effectiveness & $\begin{array}{l}\text { Overall } \\
\text { level of } \\
\text { evidence }\end{array}$ & $\begin{array}{l}\text { Guideline } \\
\text { determination }\end{array}$ & Comments \\
\hline Allopurinol & $\mathrm{PO}$ & $\begin{array}{l}\text { Hematological } \\
\text { and solid } \\
\text { cancers }\end{array}$ & $\mathrm{CT}$ & $\mathrm{P}$ & Howell 1981 [13] & $\mathrm{N}$ & $\mathrm{V}$ & \multirow[t]{2}{*}{$\begin{array}{l}\text { No guideline } \\
\text { possible }\end{array}$} & \multirow{12}{*}{$\begin{array}{l}\text { Conflicting results } \\
\text { not permitting } \\
\text { a guideline }\end{array}$} \\
\hline Allopurinol & $\mathrm{PO}$ & $\begin{array}{l}\text { Hematological } \\
\text { and solid } \\
\text { cancers }\end{array}$ & $\mathrm{CT}$ & $\mathrm{P}$ & Kroener 1982 [14] & $\mathrm{N}$ & & & \\
\hline Allopurinol & $\mathrm{PO}$ & Solid cancers & $\mathrm{CT}$ & $P$ & Howell 1983 [15] & $\mathrm{N}$ & $\mathrm{V}$ & $\begin{array}{l}\text { No guideline } \\
\text { possible }\end{array}$ & \\
\hline Allopurinol & Mouth ice ball & Colon cancer & $\mathrm{CT}$ & $\mathrm{P}$ & Yokomizo 2004 [16] & $\mathrm{Y}$ & IV & $\begin{array}{l}\text { No guideline } \\
\text { possible }\end{array}$ & \\
\hline Allopurinol & Mouthwash & Solid cancers & $\mathrm{CT}$ & $\mathrm{P}$ & Panahi 2010 [17] & $\mathrm{N}$ & II & \multirow{7}{*}{$\begin{array}{l}\text { No guideline } \\
\text { possible }\end{array}$} & \\
\hline Allopurinol & Mouthwash & Solid cancers & $\mathrm{CT}$ & $\mathrm{P}$ & Loprinzi 1990 [18] & $\mathrm{N}$ & & & \\
\hline Allopurinol & Mouthwash & Solid cancers & $\mathrm{CT}$ & $\mathrm{P}$ & Clark 1985 [19] & $\mathrm{Y}$ & & & \\
\hline Allopurinol & Mouthwash & Solid cancers & $\mathrm{CT}$ & $\mathrm{P}$ & Tsavaris 1988 [20] & $\mathrm{Y}$ & & & \\
\hline Allopurinol & Mouthwash & Solid cancers & $\mathrm{CT}$ & $P$ & Tsavaris 1991 [21] & $\mathrm{Y}$ & & & \\
\hline Allopurinol & Mouthwash & Solid cancers & $\mathrm{CT}$ & $\mathrm{P}$ & Elzawawy 1991 [22] & Y & & & \\
\hline Allopurinol & Mouthwash & Solid cancers & $\mathrm{CT}$ & $P$ & van der Vliet 1989 [23] & $\mathrm{N}$ & & & \\
\hline Allopurinol & Mouthwash & Solid cancers & $\mathrm{CT}$ & $\mathrm{T}$ & Porta 1994 [24] & $\mathrm{Y}$ & III & $\begin{array}{l}\text { No guideline } \\
\text { possible }\end{array}$ & \\
\hline
\end{tabular}

$C T$ chemotherapy, $P O$ per os, $P$ prevention, $T$ treatment, $N$ no, $Y$ yes 


\section{Midline mucosa-sparing blocks}

Table 2 summarizes the results on the use of midline mucosasparing blocks.

A retrospective study conducted over 13 years (19801993) examined the use of midline mucosa-sparing blocks (MSB) during radiation for carcinomas of the oral cavity, oropharynx and nasopharynx to ascertain whether there was a decrease in acute toxicities. Sixty-one patients received a MSB while 64 did not. The findings indicate that the MSB group had significantly less weight loss, fewer hospitalizations for nutritional support, and fewer unplanned RT interruptions [25]. MSBs were noted to be controversial because of the concern that micrometastases might be blocked from the treatment field. However, no significant difference was found in three year tumor recurrence with MSB versus no MSB.

No guideline was possible due to insufficient evidence.

\section{Payayor}

Payayor (Clinachantus nutans) is a traditional herbal medicine originating from Thailand. Payayor contains flavonoids and glycosides with sulfur compounds, and encompasses anti-inflammatory and analgesic properties. Table 2 summarizes the results on the use of payayor. A randomized controlled trial found that topical glycerin payayor was more effective than benzydamine hydrochloride mouthrinse in delaying the onset of radiation-induced OM in head and neck cancer patients [26]. No placebo was used in this study.

No guideline was possible due to insufficient evidence.

\section{Pentoxifylline}

Pentoxifylline (PTX) is used for patients with peripheral arterial disease and improves blood flow by decreasing its viscosity. It is also thought to have some anti-inflammatory properties. Therefore, it has been hypothesized that PTX administration could decrease bone marrow transplantation (BMT)-associated toxicities including mucositis [27]. Table 3 summarizes the results of the systematic review on the use of PTX.

There were a total of four publications on systemic PTX administered orally in BMT patients for the prevention of OM. The only study that reported a benefit was an open label phase I study in BMT patients that reported a lower incidence of OM as compared to historical controls [28]. However, the other three studies all found no benefit of PTX. A prospective randomized controlled trial in BMT patients has shown no statistically significant benefit in using systemic PTX compared to a control group [27]. An 
Table 3 Summary of study findings for pentoxifylline

\begin{tabular}{|c|c|c|c|c|c|c|c|c|c|}
\hline $\begin{array}{l}\text { Name } \\
\text { of } \\
\text { agent }\end{array}$ & $\begin{array}{l}\text { Route of } \\
\text { administration }\end{array}$ & Cancer type & $\begin{array}{l}\text { Treatment } \\
\text { modality }\end{array}$ & Indication & $\begin{array}{l}\text { Author, } \\
\text { year }\end{array}$ & Effectiveness & $\begin{array}{l}\text { Overall } \\
\text { level of } \\
\text { evidence }\end{array}$ & $\begin{array}{l}\text { Guideline } \\
\text { determination }\end{array}$ & Comments \\
\hline PTX & $\mathrm{PO}$ & $\begin{array}{l}\text { Hematological } \\
\text { cancers }\end{array}$ & HSCT & $\mathrm{P}$ & Attal 1993 [27] & $\mathrm{N}$ & III & $\begin{array}{l}\text { Suggestion not to use } \\
\text { oral PTX for the }\end{array}$ & \\
\hline PTX & $\mathrm{PO}$ & $\begin{array}{l}\text { Hematological } \\
\text { cancers }\end{array}$ & HSCT & $\mathrm{P}$ & Bianco 1991 [28] & Y & & $\begin{array}{l}\text { prevention of oral } \\
\text { mucositis in patients }\end{array}$ & \\
\hline PTX & $\mathrm{PO}$ & $\begin{array}{l}\text { Hematological } \\
\text { cancers }\end{array}$ & HSCT & $\mathrm{P}$ & $\begin{array}{r}\text { Van der Jagt } \\
1994 \text { [29] }\end{array}$ & $\mathrm{N}$ & & undergoing HSCT & \\
\hline PTX & $\mathrm{PO}$ & $\begin{array}{l}\text { Hematological } \\
\text { and other } \\
\text { cancers }\end{array}$ & HSCT & $\mathrm{P}$ & Ferra 1997 [30] & $\mathrm{N}$ & & & $\begin{array}{l}\text { Prophylaxis included } \\
\text { prednisone and } \\
\text { ciprofloxacin in } \\
\text { addition to PTX }\end{array}$ \\
\hline PTX & IV & $\begin{array}{l}\text { Hematological } \\
\text { cancers }\end{array}$ & HSCT & $\mathrm{P}$ & $\begin{array}{c}\text { Stockschlader } \\
1993[31]\end{array}$ & $\mathrm{N}$ & IV & No guideline possible & $(n=31)$ \\
\hline PTX & $\mathrm{PO}$ & Solid cancers & $\mathrm{CT}$ & $\mathrm{P}$ & Verdi 1995 [32] & $\mathrm{N}$ & III & No guideline possible & $(n=10)$ \\
\hline
\end{tabular}

$P T X$ pentoxifylline, $C T$ chemotherapy, $H S C T$ hematopoietic stem cell transplantation, $P O$ per os, $I V$ intravenous, $P$ prevention, $N$ no, $Y$ yes

unblinded prospective study on BMT recipients with a historical control group found no benefit from the use of systemic PTX in the prevention of OM [29]. Another casecontrol study using a combination of PTX, ciprofloxacin and prednisolone in the prevention of BMT-associated toxicities also found no benefit [30]. Collectively, the evidence supported a suggestion against the use of pentoxifylline for prevention of $\mathrm{OM}$ in this setting.

Guideline: The panel suggests that systemic pentoxifylline, administered orally, not be used for the prevention of oral mucositis in patients undergoing bone marrow transplantation (level III evidence).

A single case-control study among BMT patients using PTX intravenously also did not demonstrate a beneficial effect in the prevention of OM [31].

Lastly, a double-blind, placebo-controlled randomized crossover trial using systemic PTX administered orally for the prevention of OM induced by standard-dose $\mathrm{CT}$ also did not show a beneficial effect [32].

No guideline was possible in these treatment settings due to insufficient evidence.

\section{Radiation therapy (timing morning versus late afternoon)}

The rationale behind different timing of RT during the day is a circadian rhythm in the oral mucosal cell mitotic activity. It has been suggested that a higher prevalence of more radiosensitive cells in the mitosis phase are present in the evening compared to a higher prevalence of cells in the less radiosensitive gap 1 phase in the morning. Table 2 summarizes the results on the use of timing of RT (morning versus late afternoon). Two randomized, controlled trials assessed the influence of RT administered in the morning versus late afternoon on prevention of OM. One study did not find a significant effect on grades of OM [33]. Also, the other study did not find an overall effect, but reported a reduction in severity of $\mathrm{OM}$ in a subgroup of patients receiving $\geq 66 \mathrm{~Gy}$ and in patients who smoked during RT [34]. The study design and implementation had significant limitations in both studies. No guideline was possible due to insufficient evidence.

\section{Stimulation or inhibition of salivary gland secretion}

Table 4 summarizes the results of the systematic review on the use of agents that affect salivary secretion.

Pilocarpine

Pilocarpine is a cholinergic agonist with mainly non-selective muscarinic action but also mild beta-adrenergic activity that stimulates salivary secretion [35].

A phase III study randomized 245 subjects to pilocarpine or placebo during RT for head and neck cancer. No effect on $\mathrm{OM}$ was found [36]. Another phase III study in a similar population randomized 130 subjects to pilocarpine or placebo during RT and for one month after [37]. Once again there was no difference in the severity of OM between the two arms. These studies supported a new suggestion against the use of pilocarpine for prevention of $\mathrm{OM}$ in this setting.

Guideline: The panel suggests that systemic pilocarpine administered orally not be used for the prevention of oral mucositis during radiation therapy in head and neck cancer patients (Level III evidence).

A single study assessed systemic pilocarpine administered orally for the prevention of oropharyngeal mucositis in patients 


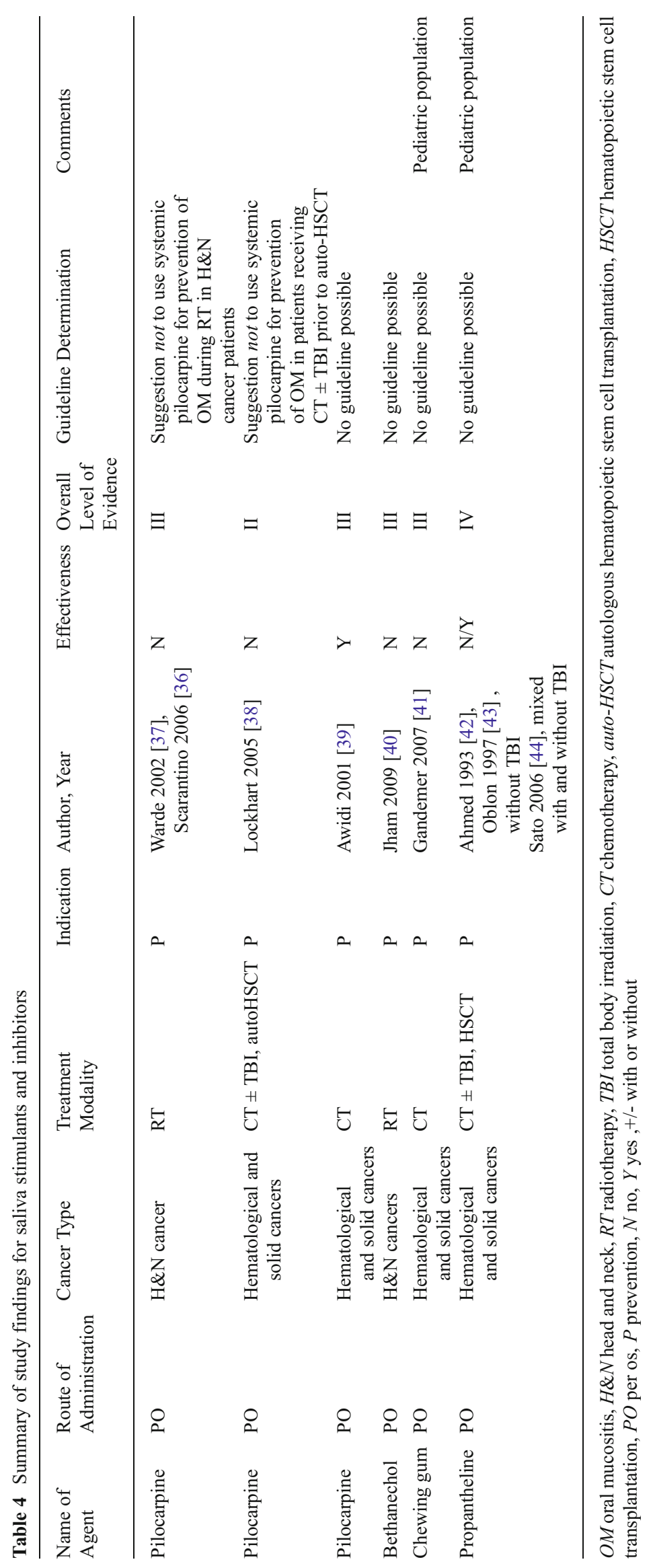


receiving high-dose $\mathrm{CT}$, with or without total body irradiation, prior to autologous HSCT [38]. No benefit of pilocarpine was found on the incidence, severity or duration of mucositis. This was a prospective, double-blind, randomized controlled trial that did not have any major flaws according to the Hadorn criteria. However, due to the small sample size $(n=36)$ of this single study, the panel decided not to develop a recommendation in this setting, instead opting for a new suggestion.

Guideline: The panel suggests that systemic pilocarpine administered orally not be used for the prevention of oral mucositis in patients receiving high-dose chemotherapy, with or without total body irradiation, prior to hematopoietic stem cell transplantation (Level II evidence).

A single cross-over study with major flaws found a beneficial effect of pilocarpine in the prevention of moderate-dose CT-induced OM [39].

No guideline was possible due to insufficient evidence.

Bethanechol

Bethanechol is a cholinergic agonist with selective muscarinic action, which is indicated and U.S. Food and Drug Administration-approved for treatment of urinary retention. The drug is used off label as a sialagogue for patients who cannot tolerate other muscarinic agonists.

One study assessed the salivary stimulatory effect of systemic bethanechol administered orally during RT in head and neck cancer patients and found no reduction in prevalence or severity of OM [40].

No guideline was possible due to insufficient evidence.

\section{Chewing gum}

The use of chewing gum increases salivary flow through gustatory and mechanical stimulation. Only one study assessed the potential effect of chewing gum for prevention of OM in children receiving CT and reported a lack of efficacy [41].

No guideline was possible due to insufficient evidence.

Propantheline

Propantheline is a muscarinic antagonist which inhibits saliva secretion. The proposed rationale for use in prevention of $\mathrm{OM}$ is reduction of salivary excretion of cytotoxic drugs and thus reduced direct toxic effect on the oral mucosa. Propantheline was evaluated in three small studies for prevention of OM in HSCT patients, with differing results [42-44]. All the studies had significant limitations in design and implementation.

No guideline was possible due to insufficient and conflicting evidence.

The panel commented that the detrimental effects of reduced saliva secretion should be taken into consideration.
Tetrachlorodecaoxide

Tetrachlorodecaoxide (TCDO) is a drug with oxidizing and immune-modulating properties potentially influencing inflammatory reactions by downregulation and accelerating wound healing. Table 2 summarizes the results on the use of TCDO. One double-blinded, randomized placebocontrolled trial assessed the effect of TCDO administered as an oral swish and swallow solution on prevention of $\mathrm{OM}$ in hematologic and solid cancer patients having $\mathrm{CT}$ and found no effect on degree or duration of $\mathrm{OM}$, oral/esophageal pain and dysphagia, although the time interval to subjective improvement of oral pain was slightly shorter and oral intake slightly improved in the TCDO group [45].

No guideline was possible due to insufficient evidence.

\section{Discussion}

Allopurinol is a purine analog that decreases both uric acid formation and purine synthesis. It is used mainly in the treatment of hyperuricemia in recurrent episodes of gout, as well as for uric acid tophi, nephrolithiasis, chronic renal failure where nephropathy is likely to be caused by hyperuricemia and is also used preventive in cytotoxic therapy. Allopurinol is metabolized to oxypurinol ribonucleotide, which causes a build-up in the levels of orotic acid, which in turn blocks the activation of 5-FU. Theoretically, this may provide protection to normal host tissues while preserving anti-cancer activity, since normal tissues, but not all cancers, rely on this activation pathway [46]. It has also been postulated that this drug can modulate methotrexate toxicity. However, the reduction of CT-induced OM by allopurinol has been inconsistent in clinical trials. Although we reviewed 12 articles related to allopurinol for CT-induced OM, no guidelines were possible due to the conflicting evidence. Additionally and more worrisome, in some animal models, allopurinol has decreased the effectiveness of 5-FU [47]. Therefore, when considering this agent for $\mathrm{OM}$, the possibility of interference with the anti-tumor effects of 5-FU should be taken into consideration.

PTX is a xanthine derivative that is primarily used to improve blood flow in patients with peripheral arterial disease. However, it has also been shown to downregulate tumor necrosis factor- $\alpha$ (TNF- $\alpha)$ production and stimulate vascular endothelial production of prostaglandins (PG) PGI2 and PGE2. Therefore, it has been hypothesized that PTX administration could decrease BMT-associated toxicities including mucositis [27]. Adverse effects of PTX can be gastrointestinal disturbances (nausea, indigestion, diarrhea). We reviewed six articles on PTX, of which four assessed its use for the prevention of OM in patients undergoing BMT. Based on this evidence, a suggestion was developed against the use of PTX for the prevention of OM in this setting. Although no 
guideline was possible in other settings due to insufficient evidence, it is note-worthy that the available studies in other settings also failed to demonstrate a benefit of this agent.

Salivary secretion is regulated by a reflex arch and physiologically secreted into the oral cavity by three pairs of major salivary glands and multiple minor salivary glands, in response to gustatory and masticatory stimuli. The secretory reflex arch is also under the influence of autonomic centers in the brain and resting saliva can be secreted in the absence of exogenous stimuli. This secretion plays a fundamental role in lubrication of oropharyngeal and upper esophageal mucosa as well as in preventing oral infections by providing antimicrobial activity, by dilution of food detritus and bacteria, and by mechanical cleansing of the oral cavity [48]. Cytotoxic drugs used for cancer may also be secreted in saliva in various concentrations, thus enabling direct contact of these drugs with the oral mucosa. Head and neck RT induces salivary gland hypofunction dependent on the cumulative radiation dose to the secretory tissues [49]. Similarly, cancer CT may reduce saliva secretion and decrease the amount of secretory immunoglobulin A (s-IgA) [50]. Hence, cancer therapies have a significant impact on oral and digestive homeostasis through their effects on secretory function, which may result in lower quality of life, weight loss and malnutrition.

Although maintenance of physiologic levels of salivary secretion is generally beneficial, this benefit does not seem to extend to $\mathrm{OM}$. We reviewed a number of studies testing the effects of salivary stimulation on OM. Of these, two large randomized controlled trials clearly demonstrated that stimulation of salivary flow by pilocarpine had no effect on the severity of radiationinduced $\mathrm{OM}$ in head and neck cancer patients. Further, an additional small but well-designed randomized controlled trial similarly demonstrated a lack of benefit of pilocarpine for prevention of CT-induced OM in patients undergoing HSCT. Based on this evidence, we were able to develop two new suggestions against the use of pilocarpine for the prevention of OM in these settings. It is important to note that these suggestions relate specifically to the use of pilocarpine for the prevention of OM. The stimulation of salivary flow by pilocarpine or other agents may have other benefits in these patients; however, that is beyond the scope of this review. In addition to drugs, salivary gland output can also be increased through mechanical stimulation, such as by chewing gum. Such stimulation is appealing as it does not involve any medication and has no deleterious side effects. However, the single study we reviewed on chewing gum also reported a lack of benefit for OM.

Conversely, it has been hypothesized that an inhibition of salivary flow can reduce the severity of OM by reducing the amount of cytotoxic drug secreted in saliva. We reviewed three studies testing this strategy using the antimuscarinic agent propantheline in patients undergoing HSCT. These studies yielded conflicting results, precluding the development of a guideline. The principle here is somewhat similar to that of cryotherapy, where vasoconstriction of blood vessels by keeping ice chips in the mouth can reduce the severity of OM secondary to certain CT drugs. However, an important difference is that the delivery of the chemotherapeutic agent to the oral tissues is well-accepted to occur via blood. On the other hand, the contribution of the relatively low levels of chemotherapeutic agents secreted in saliva to $\mathrm{OM}$ is questionable. Furthermore, reduced saliva secretion is known to have several detrimental effects including significantly increased risk of oral infections and carious destruction of teeth, oropharyngeal mucosal dryness and discomfort as well as interference with oral functions, including impaired taste perception and difficulties with mastication, swallowing and speech [48]. Therefore, although a formal guideline was not possible due to insufficient and conflicting evidence, the general opinion of the expert panel was against the use of agents that inhibit salivary flow.

The two studies suggesting that altering the timing of RT delivery can impact severity of OM are intriguing [33, 34]. However, this may not be a strategy that is practically feasible to implement since at most centers, patients are scheduled for RT all through the day. The typical 5 days a week schedule of RT for head and neck cancer also reduces scheduling flexibility.

An additional preliminary study emerged after the inclusion period of this systematic review, reporting that transcutaneus electrical nerve stimulation (TENS) in the regions of the major salivary glands or combined TENS/masticatory stimulation applied before, during and after cancer treatment in allogeneic HSCT patients resulted in less reduction of unstimulated and stimulated whole saliva secretion as well as fewer patients affected by grades 3 and $4 \mathrm{OM}$. However, the conclusions have to be considered with precaution since the number of patients included was low and without comparison between the study and control groups regarding the neutropenia period (or at least about the myelotoxicity level of the conditioning regimen) [51].

In summary, various interventions for the management of OM were reviewed in this section. The proposed mechanisms of these interventions vary greatly. Scientific evidence suggests avoiding the use of systemic PTX and pilocarpine for the prevention of $\mathrm{OM}$ in certain cancer treatment modalities.

Disclosure The Mucositis Guidelines Update was sponsored by Helsinn Healthcare S.A., Switzerland and BioAlliance Pharma, France. Per MASCC/ISOO policy, no industry representatives had any role in the development of the guidelines. Andrei Barasch has received funding from Amgen ${ }^{\circledR}$, USA and BioAlliance Pharma, France.

\section{References}

1. Keefe DM, Schubert MM, Elting LS, Sonis ST, Epstein JB, RaberDurlacher JE, Migliorati CA, McGuire DB, Hutchins RD, Peterson DE (2007) Updated clinical practice guidelines for the prevention and treatment of mucositis. Cancer 109(5):820-831

2. Lalla RV (2013) The MASCC/ISOO mucositis guidelines update: introduction to the first set of articles. Support Care Cancer 21(1):301-302 
3. Bowen JM, Elad S, Hutchins RD, Lalla RV (2013) Methodology for the MASCC/ISOO mucositis clinical practice guidelines update. Support Care Cancer 21(1):303-308

4. Elad S, Bowen J, Zadik Y, Lalla RV (2013) Development of the MASCC/ISOO clinical practice guidelines for mucositis: considerations underlying the process. Support Care Cancer 21(1):309312

5. Gibson RJ, Keefe DM, Lalla RV, Bateman E, Blijlevens N, Fijlstra M, King EE, Stringer AM, van der Velden WJ, Yazbeck R, Elad S, Bowen JM (2013) Systematic review of agents for the management of gastrointestinal mucositis in cancer patients. Support Care Cancer 21(1):313-326

6. Nicolatou-Galitis O, Sarri T, Bowen J, Di PM, Kouloulias VE, Niscola P, Riesenbeck D, Stokman M, Tissing W, Yeoh E, Elad S, Lalla RV (2013) Systematic review of amifostine for the management of oral mucositis in cancer patients. Support Care Cancer 21(1):357364

7. Migliorati C, Hewson I, Lalla RV, Antunes HS, Estilo CL, Hodgson B, Lopes NN, Schubert MM, Bowen J, Elad S (2013) Systematic review of laser and other light therapy for the management of oral mucositis in cancer patients. Support Care Cancer 21(1):333-341

8. Peterson DE, Ohrn K, Bowen J, Fliedner M, Lees J, Loprinzi C, Mori T, Osaguona A, Weikel DS, Elad S, Lalla RV (2013) Systematic review of oral cryotherapy for management of oral mucositis caused by cancer therapy. Support Care Cancer 21(1):327-332

9. Raber-Durlacher JE, von Bültzingslöwen I, Logan RM, Bowen J, Al-Azri AR, Everaus H, Gerber E, Gomez JG, Pettersson BG, Soga Y, Spijkervet FK, Tissing WJ, Epstein JB, Elad S, Lalla RV (2013) Systematic review of cytokines and growth factors for the management of oral mucositis in cancer patients. Support Care Cancer 21(1):343-355

10. Hadorn DC, Baker D, Hodges JS, Hicks N (1996) Rating the quality of evidence for clinical practice guidelines. J Clin Epidemiol 49(7):749754

11. Somerfield MR, Einhaus K, Hagerty KL, Brouwers MC, Seidenfeld J, Lyman GH (2008) American Society of Clinical Oncology clinical practice guidelines: opportunities and challenges. J Clin Oncol 26(24):4022-4026

12. Yarom N, Ariyawardana A, Hovan A, Barasch A, Jarvis V, Jensen SB, Zadik Y, Elad S, Bowen J, Lalla RV, For the Mucositis Study Group of the Multinational Association of Supportive Care in Cancer/International Society of Oral Oncology (MASCC/ISOO) (2013) Systematic review of natural agents for the management of oral mucositis in cancer patients. Support Care Cancer. doi:10. 1007/s00520-013-1869-5

13. Howell SB, Wung WE, Taetle R, Hussain F, Romine JS (1981) Modulation of 5-fluorouracil toxicity by allopurinol in man. Cancer 48(6):1281-1289

14. Kroener JF, Saleh F, Howell SB (1982) 5-FU and allopurinol: toxicity modulation and phase II results in colon cancer. Cancer Treat Rep 66(5):1133-1137

15. Howell SB, Pfeifle CE, Wung WE (1983) Effect of allopurinol on the toxicity of high-dose 5 -fluorouracil administered by intermittent bolus injection. Cancer 51(2):220-225

16. Yokomizo H, Yoshimatsu K, Hashimoto M, Ishibashi K, Umehara A, Yoshida K, Fujimoto T, Watanabe K, Ogawa K (2004) Prophylactic efficacy of allopurinol ice ball for leucovorin/5-fluorouracil therapyinduced stomatitis. Anticancer Res 24(2C):1131-1134

17. Panahi Y, Ala S, Saeedi M, Okhovatian A, Bazzaz N, Naghizadeh MM (2010) Allopurinol mouth rinse for prophylaxis of fluorouracilinduced mucositis. Eur J Cancer Care (Engl) 19(3):308-312

18. Loprinzi CL, Cianflone SG, Dose AM, Etzell PS, Burnham NL, Therneau TM, Hagen L, Gainey DK, Cross M, Athmann LM (1990) A controlled evaluation of an allopurinol mouthwash as prophylaxis against 5-fluorouracil-induced stomatitis. Cancer 65(8):1879-1882
19. Clark PI, Slevin ML (1985) Allopurinol mouthwashes and 5fluorouracil induced oral toxicity. Eur J Surg Oncol 11(3):267-268

20. Tsavaris N, Caragiauris P, Kosmidis P (1988) Reduction of oral toxicity of 5-fluorouracil by allopurinol mouthwashes. Eur J Surg Oncol 14(5):405-406

21. Tsavaris NB, Komitsopoulou P, Tzannou I, Loucatou P, TsarouchaNoutsou A, Kilafis G, Kosmidis P (1991) Decreased oral toxicity with the local use of allopurinol in patients who received high dose 5-fluorouracil. Sel Cancer Ther 7(3):113-117

22. Elzawawy A (1991) Treatment of 5-fluorouracil-induced stomatitis by allopurinol mouthwashes. Oncology 48(4):282-284

23. Van der Vliet W, Erlichman C, Elhakim T (1989) Allopurinol mouthwash for prevention of fluorouracil-induced stomatitis. Clin Pharm 8(9):655-658

24. Porta C, Moroni M, Nastasi G (1994) Allopurinol mouthwashes in the treatment of 5-fluorouracil-induced stomatitis. Am J Clin Oncol 17(3):246-247

25. Perch SJ, Machtay M, Markiewicz DA, Kligerman MM (1995) Decreased acute toxicity by using midline mucosa-sparing blocks during radiation therapy for carcinoma of the oral cavity, oropharynx, and nasopharynx. Radiology 197(3):863-866

26. Putwatana P, Sanmanowong P, Oonprasertpong L, Junda T, Pitiporn S, Narkwong L (2009) Relief of radiation-induced oral mucositis in head and neck cancer. Cancer Nurs 32(1):82-87

27. Attal M, Huguet F, Rubie H, Charlet JP, Schlaifer D, Huynh A, Laurent G, Pris J (1993) Prevention of regimen-related toxicities after bone marrow transplantation by pentoxifylline: a prospective, randomized trial. Blood 82(3):732-736

28. Bianco JA, Appelbaum FR, Nemunaitis J, Almgren J, Andrews F, Kettner P, Shields A, Singer JW (1991) Phase I-II trial of pentoxifylline for the prevention of transplant-related toxicities following bone marrow transplantation. Blood 78(5):1205-1211

29. van der Jagt RH, Pari G, McDiarmid SA, Boisvert DM, Huebsch LB (1994) Effect of pentoxifylline on regimen related toxicity in patients undergoing allogeneic or autologous bone marrow transplantation. Bone Marrow Transplant 13(2):203-207

30. Ferra C, de Sanjose S, Lastra CF, Marti F, Marino EL, Sureda A, Brunet S, Gallardo D, Berlanga JJ, Garcia J, Granena A (1997) Pentoxifylline, ciprofloxacin and prednisone failed to prevent transplant-related toxicities in bone marrow transplant recipients and were associated with an increased incidence of infectious complications. Bone Marrow Transplant 20(12):10751080

31. Stockschlader M, Kalhs P, Peters S, Zeller W, Kruger W, Kabisch H, Lechner K, Zander A (1993) Intravenous pentoxifylline failed to prevent transplant-related toxicities in allogeneic bone marrow transplant recipients. Bone Marrow Transplant 12(4):357-362

32. Verdi CJ, Garewal HS, Koenig LM, Vaughn B, Burkhead T (1995) A double-blind, randomized, placebo-controlled, crossover trial of pentoxifylline for the prevention of chemotherapy-induced oral mucositis. Oral Surg Oral Med Oral Pathol Oral Radiol Endod 80(1):36-42

33. Goyal M, Shukla P, Gupta D, Bisht SS, Dhawan A, Gupta S, Pant MC, Verma NS (2009) Oral mucositis in morning vs. evening irradiated patients: a randomised prospective study. Int J Radiat Biol 85(6):504-509

34. Bjarnason GA, Mackenzie RG, Nabid A, Hodson ID, El-Sayed S, Grimard L, Brundage M, Wright J, Hay J, Ganguly P, Leong C, Wilson J, Jordan RC, Walker M, Tu D, Parulekar W (2009) Comparison of toxicity associated with early morning versus late afternoon radiotherapy in patients with head-and-neck cancer: a prospective randomized trial of the National Cancer Institute of Canada Clinical Trials Group (HN3). Int J Radiat Oncol Biol Phys 73(1):166-172

35. Fox PC, Atkinson JC, Macynski AA, Wolff A, Kung DS, Valdez IH, Jackson W, Delapenha RA, Shiroky J, Baum BJ (1991) 
Pilocarpine treatment of salivary gland hypofunction and dry mouth (xerostomia). Arch Intern Med 151(6):1149-1152

36. Scarantino C, LeVeque F, Swann RS, White R, Schulsinger A, Hodson DI, Meredith R, Foote R, Brachman D, Lee N (2006) Effect of pilocarpine during radiation therapy: results of RTOG 97-09, a phase III randomized study in head and neck cancer patients. J Support Oncol 4(5):252-258

37. Warde P, O'Sullivan B, Aslanidis J, Kroll B, Lockwood G, Waldron J, Payne D, Bayley A, Ringash J, Kim J, Liu FF, Maxymiw W, Sprague S, Cummings BJ (2002) A Phase III placebo-controlled trial of oral pilocarpine in patients undergoing radiotherapy for head-and-neck cancer. Int J Radiat Oncol Biol Phys 54(1):9-13

38. Lockhart PB, Brennan MT, Kent ML, Packman CH, Norton HJ, Fox PC, Frenette G (2005) Randomized controlled trial of pilocarpine hydrochloride for the moderation of oral mucositis during autologous blood stem cell transplantation. Bone Marrow Transplant 35(7):713-720

39. Awidi A, Homsi U, Kakail RI, Mubarak A, Hassan A, Kelta M, Martinez P, Sulaiti S, Al QA, Jamhoury A, Daniel M, Charles C, Ambrose A, El-Aloosy AS (2001) Double-blind, placebocontrolled cross-over study of oral pilocarpine for the prevention of chemotherapy-induced oral mucositis in adult patients with cancer. Eur J Cancer 37(16):2010-2014

40. Jham BC, Chen H, Carvalho AL, Freire AR (2009) A randomized phase III prospective trial of bethanechol to prevent mucositis, candidiasis, and taste loss in patients with head and neck cancer undergoing radiotherapy: a secondary analysis. JOral Sci 51(4):565-572

41. Gandemer V, Le Deley MC, Dollfus C, Auvrignon A, BonnaureMallet M, Duval M, De LL, Hartmann O, Mechinaud F, Sirvent N, Orbach D, Doireau V, Boutard P, Dalle JH, Reguerre Y, Pautard B, Aubier F, Schneider P, Suc A, Couillaut G, Schmitt C (2007) Multicenter randomized trial of chewing gum for preventing oral mucositis in children receiving chemotherapy. J Pediatr Hematol Oncol 29(2):86-94

42. Ahmed T, Engelking C, Szalyga J, Helson L, Coombe N, Cook P, Corbi D, Puccio C, Chun H, Mittelman A (1993) Propantheline prevention of mucositis from etoposide. Bone Marrow Transplant 12(2):131-132
43. Oblon DJ, Paul SR, Oblon MB, Malik S (1997) Propantheline protects the oral mucosa after high-dose ifosfamide, carboplatin, etoposide and autologous stem cell transplantation. Bone Marrow Transplant 20(11):961-963

44. Sato A, Saisho-Hattori T, Koizumi Y, Minegishi M, Inuma K, Imaizumi M (2006) Prophylaxis of mucosal toxicity by oral propantheline and cryotherapy in children with malignancies undergoing myeloablative chemo-radiotherapy. Tohoku J Exp Med 210(4):315-320

45. Malik IA, Moid I, Haq S, Sabih M (1997) A double-blind, placebocontrolled, randomized trial to evaluate the role of tetrachlorodecaoxide in the management of chemotherapy-induced oral mucositis. J Pain Symptom Manage 14(2):82-87

46. Schwartz PM, Handschumacher RE (1979) Selective antagonism of 5-fluorouracil cytotoxicity by 4-hydroxypyrazolopyrimidine (allopurinol) in vitro. Cancer Res 39(8):3095-3101

47. Berne M, Gustavsson B, Almersjo O, Spears CP, Waldenstrom J (1987) Concurrent allopurinol and 5-fluorouracil: 5-fluoro-2'deoxyuridylate formation and thymidylate synthase inhibition in rat colon carcinoma and in regenerating rat liver. Cancer Chemother Pharmacol 20(3):193-197

48. Pedersen AM, Bardow A, Jensen SB, Nauntofte B (2002) Saliva and gastrointestinal functions of taste, mastication, swallowing and digestion. Oral Dis 8(3):117-129

49. Vissink A, Mitchell JB, Baum BJ, Limesand KH, Jensen SB, Fox PC, Elting LS, Langendijk JA, Coppes RP, Reyland ME (2010) Clinical management of salivary gland hypofunction and xerostomia in head and neck cancer patients: successes and barriers. Int J Radiat Oncol Biol Phys 78(4):983-991

50. Jensen SB, Mouridsen HT, Reibel J, Brünner N, Nauntofte B (2008) Adjuvant chemotherapy in breast cancer patients induces temporary salivary gland hypofunction. Oral Oncology 44(2):162-173

51. Amaral TMP, Campos CC, Santos TPM, Leles CR, Teixeira AL, Teixeira MM, Bittencourt H, Silva TA (2012) Effect of salivary stimulation therapies on salivary flow and chemotherapy-induced mucositis: a preliminary study. Oral Surg Oral Med Oral Pathol Oral Radiol 113(5):628-637 